\title{
Sign of Life is Associated with Return of Spontaneous Circulation After Resuscitative Thoracotomy: Single Trauma Center Experience of Republic of Korea
}

\author{
Byung Hee Kang ${ }^{1} \cdot$ Donghwan Choi $^{1} \cdot$ Yo Huh $^{1} \cdot$ Junsik Kwon $^{1} \cdot$ Kyoungwon Jung $^{1} \cdot$ \\ John Cook-Jong Lee ${ }^{1} \cdot$ Jonghwan Moon ${ }^{1}$
}

Published online: 8 February 2019

(C) Société Internationale de Chirurgie 2019

\begin{abstract}
Background Resuscitative thoracotomy (RT) can be a lifesaving treatment, but it has not yet been performed in Korea. In this study, we review our experience of RT after a regional trauma center was constructed.

Methods This is a retrospective study of RT conducted at a single Korean trauma center from May 2014 to March 2018. The primary outcome was survival, and the secondary outcome was return of spontaneous circulation (ROSC). The clinical characteristics of the patients were compared between the ROSC and non-ROSC groups. Survivors were also reviewed.

Results A total of 62 patients were reviewed, and 60 patients had experienced blunt injury. Thirty-nine patients had ROSC. The ROSC group had short cardiopulmonary resuscitation (CPR) time (6 [2-10] min vs 11 [8-12] min, $p<0.001)$, the presence of sign of life at the trauma bay [32 (86.5\%) vs $7(28.0 \%), p<0.001]$, and a low Injury Severity Score [26 (25-39) vs $37(30-75), p=0.038]$ compared to the non-ROSC group. On multivariate analysis, only the presence of sign of life was significantly associated with ROSC [11.297 (1.496-85.309) OR (95\% CI), $p=0.019$ ] . The 24 -h survival rate was $8.1 \%$, and the successful discharge rate was $4.8 \%$.

Conclusion The outcome of RT in a Korean trauma center was favorable. ROSC after RT was strongly associated with the presence of sign of life, and RT may be performed in the presence of sign of life regardless of prehospital CPR time.
\end{abstract}

\section{Introduction}

Resuscitative thoracotomy (RT) is considered the last option when performing resuscitation on cardiac arrest patients with severe trauma. It can be performed for several reasons, such as to release the pericardial tamponade, control cardiac hemorrhage, control intrathoracic bleeding, evacuate a massive air embolism, perform open cardiac massage, and temporarily occlude the descending thoracic

Jonghwan Moon

soyo1226@naver.com

1 Department of Trauma Surgery, Ajou University School of Medicine, 164 Worldcup-ro, Yeongtong-gu, Suwon 16499, Republic of Korea aorta [1]. RT is performed not only in thoracic trauma patients but also in non-thoracic trauma patients for resuscitation; therefore, it differs from emergency thoracotomy performed in the operation room [2]. With strict indications, the overall survival rate after RT has improved from 5 to $14 \%$, but performing the procedure after a blunt trauma remains controversial [3].

Because RT requires many resources such as skills, manpower, facilities, and time, it was impossible to previously perform it in Korea. Moreover, blunt trauma, for which RT is not effective, is a major occurrence in Korea [4]. However, the Korean trauma system has been recently established with the creation of regional trauma centers all over the country since 2012 [5]. Our institution is one of such trauma centers and has been trying to improve the 
trauma system, including RT. To the best of our knowledge, until recently, our institution was only center that actively performed RT in Korea.

Many reports on RT are available in the USA, and only a few have been published in Asia, especially in Japan [6-8]. Therefore, the aim of our study was to review the experience and outcome of RT at a trauma center in Korea.

\section{Methods}

This was a retrospective study conducted from May 2014 to March 2018 and was approved by the Institutional Review Board of our institution (AJIRB-MED-OBS-18126). Our center was nominated as a regional level I trauma center at the end of 2012, but until 2015, the resources were limited, and emergency physicians usually examined severe trauma patients first. With national support, a new trauma center was constructed in 2016 and trauma bay has been operated separately from emergency room. RT was initiated just before the dedicated trauma bay opened and has been performed more frequently since the transition. However, the RT protocol has not changed.

Prehospital variables including injury mechanism, injury time, and prehospital cardiopulmonary resuscitation (CPR) times were collected from prehospital records. In addition, as CPR time is an indication for RT, we asked emergency medical service (EMS) personnel and recorded the prehospital CPR times. Baseline demographic and clinical data were collected from medical record and surgical descriptions. Sign of life in the trauma bay was defined as the presence of one of following: detectable blood pressure, respiratory or motor effort, cardiac electric activity, and pupillary activity. Injury Severity Score (ISS) was calculated by a trauma coordinator. However, since autopsy is not routinely performed in Korea, ISS could not be calculated in some deceased patients. Nevertheless, major injury sites could be identified because sonography and simple radiography were performed for suspicious lesion after death. Major injury sites and cause of cardiac arrest were obtained from death certificates, ISS, and medical chart provided by the attending staff. Major injury sites were defined according to ISS lesions.

In-hospital mortality was the primary outcome, but only few patients were expected to survive. Therefore, return of spontaneous circulation (ROSC) after RT was the secondary outcome. The study flow is presented in Fig. 1.

\section{Resuscitative thoracotomy indication}

The following indications of RT at our institution were according to the current guidelines [9, 10]: (1) blunt trauma with prehospital cardiac arrest time $<10 \mathrm{~min}$,

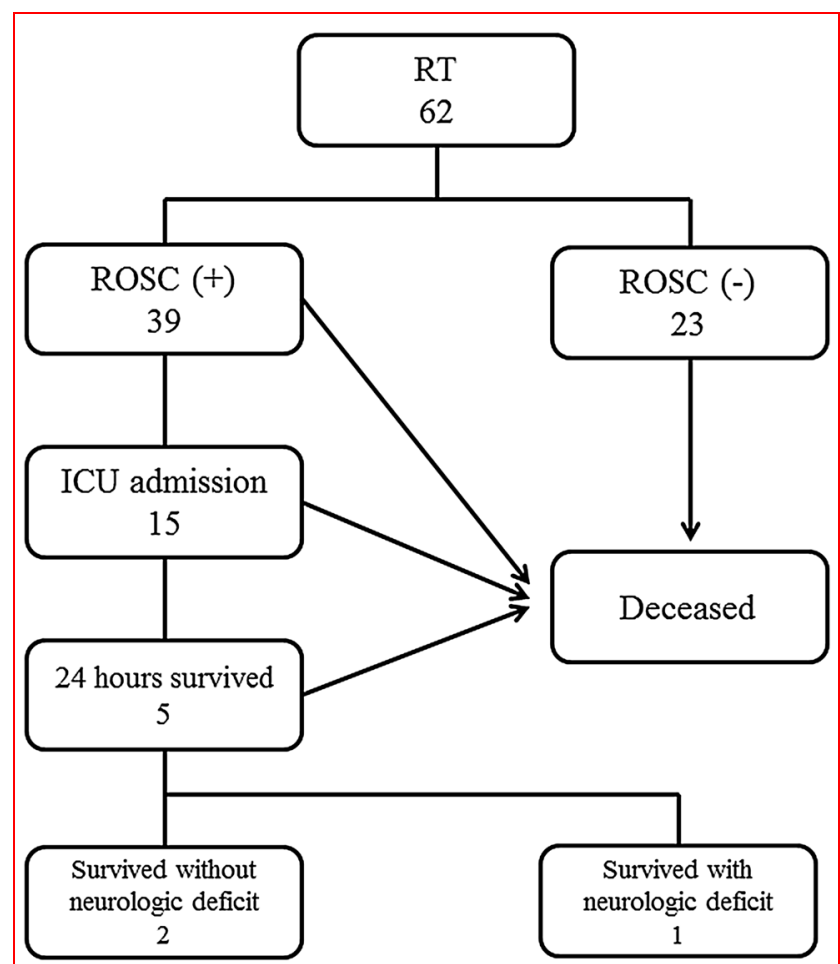

Fig. 1 Flowchart of the study. RT; resuscitative thoracotomy; ROSC, return of spontaneous circulation; ICU, intensive care unit

penetrating trauma with prehospital cardiac arrest time $<$ $15 \mathrm{~min}$, and (3) impending cardiac arrest.

RT was usually performed in the trauma bay; however, if the patient information was known to us, i.e., they were transferred from a local hospital, the patient was directly admitted to the operation room (OR) and RT was performed there regardless of ROSC. In addition, because trauma surgeons participate in physician-staffed helicopter EMS in our trauma center, sometimes RT is performed in a helicopter if indicated [11]. If ROSC was observed in the trauma bay, the patient was immediately transferred to OR to control hemorrhage.

\section{Surgical technique}

Trauma surgeons certified by the boards of general surgery, thoracic surgery, or emergency medicine performed RT. Left anterolateral thoracotomy was performed in the fifth intercostal space. After dissection with a scalpel or metzenbaum scissor, a rib spreader was used. Cross-clamping of the descending aorta was routinely conducted, and open cardiac massage was performed. If needed, we extended the incision into clamshell type; however, it was not performed in the trauma bay but in OR. 


\section{Statistical analysis}

Continuous variables were expressed as median values and interquartile ranges because they did not follow normal distribution. Categorical variables were presented numbers. Chi-square test and Fisher's exact test, and Mann-Whitney $\mathrm{U}$ test were applied for categorical and continuous variables, respectively. To identify the associated factors for ROSC after RT, univariate analysis was performed to compare the ROSC and non-ROSC groups. The presence of sign of life, CPR time, ISS, sex, age, admission route, injury mechanism, admission time from injury, and cause of cardiac arrest were selected for univariate analysis. Multivariate analysis was performed using logistic regression with an enter method, and variables were selected for inclusion in the model on the basis of the results of the univariate analysis. A p value of $<0.10$ was considered statistically significant. SPSS version 23 (IBM, Chicago, IL, USA) was used for analysis.

\section{Results}

\section{Patients' characteristics}

A total of 62 patients underwent RT during the 4-year study period. Most patients were men with blunt trauma, and median age was 52 years. Two patients with penetrating trauma had thorax injury. Thirty-nine patients experienced ROSC after RT. The baseline characteristics are presented in Table 1. The ROSC group presented shorter CPR times than the non-ROSC group (6 [2-10] min vs 11 [8-12] min, $p<0.001)$, more presence of sign of life in the trauma bay (32 $(86.5 \%)$ vs $7(28.0 \%), p<0.001)$, and less ISS (26 [25-39] vs 37 [30-75], $p=0.038$ ). However, ISS could not be calculated for nine patients in each group because adequate evaluation was not performed. Two cases of RT were performed in the helicopter, and although they experienced ROSC, none survived.

Table 1 Baseline demographic characteristics

\begin{tabular}{|c|c|c|c|c|}
\hline & All (62) & ROSC (39) & Non-ROSC (23) & $p$ \\
\hline Age (years) & $52[37-67]$ & $47[35-62]$ & $62[45-74]$ & 0.374 \\
\hline Sex $(M / F$ ratio $)$ & $47: 15$ & $27: 12$ & $20: 3$ & 0.115 \\
\hline Injury mechanism & & & & 0.701 \\
\hline Blunt & 60 & 38 & 22 & \\
\hline Penetrating & 2 & 1 & 1 & \\
\hline $\mathrm{ISS}^{\dagger}$ & $31[25-41]$ & 26 [25-39] & 37 [30-75] & 0.038 \\
\hline CPR time before RT (min) & $9[4-11]$ & $6[2-10]$ & $11[8-12]$ & $<0.001$ \\
\hline Presence of sign of life & 37 & 32 & 5 & $<0.001$ \\
\hline Admission time from injury (min) & 38 [25-127] & $38[22-154]$ & $62[27-123]$ & 0.959 \\
\hline Admission route & & & & 0.425 \\
\hline Direct & 42 & 25 & 17 & \\
\hline Transfer & 20 & 14 & 6 & \\
\hline Major injury site & & & & 0.176 \\
\hline Head & 8 & 3 & 5 & \\
\hline Thorax & 28 & 16 & 12 & \\
\hline Abdomen & 15 & 12 & 3 & \\
\hline Pelvic or extremity & 11 & 8 & 3 & \\
\hline Cause of cardiac arrest & & & & $0.134^{\mathrm{a}}$ \\
\hline Bleeding & 54 & 36 & 18 & \\
\hline Brain & 8 & 3 & 5 & \\
\hline
\end{tabular}

Values in parenthesis are median [quartile]

$R O S C$ return of spontaneous circulation after resuscitative thoracotomy, ISS Injury Severity Score, $C P R$ cardiopulmonary resuscitation, and $R T$ resuscitative Thoracotomy

${ }^{\dagger} 18$ patients could not be calculated the ISS. Nine patients in each group could not be calculated the ISS

${ }^{a}$ Fisher's exact test 
Table 2 Location of RT

\begin{tabular}{lllll}
\hline & Trauma bay (45) & OR (15) & Helicopter (2) \\
\hline Age (years) & $47[36-64]$ & $52[38-62]$ & $47[24-69]$ & 0.771 \\
Sex (M/F ratio) & $33: 12$ & $13: 2$ & $1: 1$ & $32[26-38]$ \\
ISS & $34[25-54]$ & $26[25-32]$ & 5.398 \\
CPR time before RT (min) & $9[5-11]$ & $5[1-11]$ & $12(80.0 \%)$ & 0.466 \\
Presence of sign of life & $25(55.6 \%)$ & $11(73.3 \%)$ & $2(100 \%)$ & 0.476 \\
ROSC & $26(57.8 \%)$ & $2(13.3 \%)$ & $0(0 \%)$ & 0.054 \\
Survival & $2(4.4 \%)$ & & 0.446 \\
\hline
\end{tabular}

Values in parenthesis are median [quartile]

$O R$ operation room, ISS Injury Severity Score, $C P R$ cardiopulmonary resuscitation, $R T$ resuscitative thoracotomy, and $R O S C$ return of spontaneous circulation after resuscitative thoracotomy

Table 3 Univariate analysis of associated factors for ROSC

\begin{tabular}{|c|c|c|c|}
\hline & $\begin{array}{l}\text { Odds } \\
\text { ratio }\end{array}$ & $\begin{array}{l}95 \% \text { Confidence } \\
\text { interval }\end{array}$ & $p$ \\
\hline Presence of sign of life & 16.457 & $4.554-59.471$ & $<0.001$ \\
\hline CPR time & 0.767 & $0.655-0.897$ & 0.001 \\
\hline ISS & 0.961 & $0.926-0.998$ & 0.040 \\
\hline \multicolumn{4}{|l|}{ Injury site } \\
\hline $\begin{array}{l}\text { Head/thorax } \\
\text { (reference) }\end{array}$ & 1.000 & & \\
\hline Abdomen/pelvic ${ }^{\mathrm{a}}$ & 2.982 & $0.970-9.166$ & 0.056 \\
\hline Sex (female) & 2.963 & $0.737-11.908$ & 0.126 \\
\hline Age & 0.987 & $0.960-1.015$ & 0.987 \\
\hline Admission route & 1.587 & $0.509-4.950$ & 0.426 \\
\hline Injury mechanism & 0.579 & $0.034-9.724$ & 0.704 \\
\hline $\begin{array}{l}\text { Admission time from } \\
\text { injury }\end{array}$ & 1.001 & $0.997-1.006$ & 0.532 \\
\hline Cause of cardiac arrest & 0.300 & $0.064-1.398$ & 0.125 \\
\hline
\end{tabular}

ROSC return of spontaneous circulation after resuscitative thoracotomy, $C P R$ cardiopulmonary resuscitation, and ISS Injury Severity Score

\section{Location of RT}

Of 62 patients, 42 underwent RT in the new trauma bay, 15 in the OR, three in the original emergency department, and two in the transport helicopter. No significant difference was observed between location and ROSC rate. Two patients who were performed RT in helicopter presented ROSC after RT, but did not survive (Table 2).

\section{Associated factors of ROSC after RT}

In the univariate analysis, the presence of sign of life, CPR time, abdomen/pelvic injury, and ISS were selected for multivariate analysis (Table 3). However, only the presence of sign of life (11.297 [1.496-85.309] odds ratio [95\% $\mathrm{CI}], p=0.019)$ was significant in the final multivariate model (Table 4).
Table 4 Multivariate analysis of associated factors for ROSC

\begin{tabular}{lrll}
\hline & $\begin{array}{l}\text { Odds } \\
\text { ratio }\end{array}$ & $\begin{array}{l}\text { 95\% Confidence } \\
\text { interval }\end{array}$ & $p$ \\
\hline Presence of sign of life & 11.297 & $1.496-85.309$ & 0.019 \\
CPR time & 0.805 & $0.632-1.026$ & 0.079 \\
ISS & 0.967 & $0.923-1.013$ & 0.154 \\
$\begin{array}{l}\text { Injury site } \\
\quad \text { Head/thorax }\end{array}$ & 1.000 & & \\
$\quad$ (reference) & & & \\
Abdomen/pelvic & & \\
\hline
\end{tabular}

Hosmer-Lemeshow goodness of fit ( $\mathrm{DF}=8)$, Chi-square 10.030, and $p=0.263$

The presence of sign of life, CPR time, ISS, abdomen/pelvic injury, sex, age, admission route, injury mechanism, admission time from injury and cause of cardiac arrest were selected for univariate analysis. After univariate analysis, variables $(p<0.10)$ were selected for multivariate analysis and other variables $(p>0.10)$ were not presented in table

$R O S C$ return of spontaneous circulation after resuscitative thoracotomy, $C I$ confidence interval, $C P R$ cardiopulmonary resuscitation, and ISS Injury Severity Score

\section{Survivors}

Five patients survived after RT, and all patients presented signs of life (Table 5). However, one patient died due to septic shock 16 days postoperatively and one patient became an organ donor because of severe anoxic brain damage. Three patients were successfully discharged, and the overall survival rate was $4.8 \%$ (3/62) (Table 4). Two patients $(3.2 \%)$ were discharged without neurological deficit. A 22-year-old woman was admitted to our trauma center after a 4-m fall. She presented with cardiac arrest before arrival to the hospital. CPR was performed by EMS personnel for approximately $9 \mathrm{~min}$. After RT, circulation was recovered but active bleeding of thorax was not identified during the operation. Massive transfusion and resuscitation were performed in the intensive care unit. However, she was later diagnosed with skull fracture, brain hemorrhage, facial bone fracture, rib fracture, 
Table 5 Characteristics of survivors

\begin{tabular}{|c|c|c|c|c|c|c|c|c|}
\hline Sex/age & $\begin{array}{l}\text { Injury } \\
\text { mechanism }\end{array}$ & $\begin{array}{l}\text { CPR time } \\
(\min )\end{array}$ & $\begin{array}{l}\text { Admission from } \\
\text { injury (min) }\end{array}$ & ISS & $\begin{array}{l}\text { Major } \\
\text { injury }\end{array}$ & $\begin{array}{l}\text { ICU } \\
\text { LOS }\end{array}$ & $\begin{array}{l}\text { Ventilator } \\
\text { LOS }\end{array}$ & Outcome \\
\hline $\mathrm{M} / 51$ & Blunt & 2 & 155 & NA & Brain & 5 & 5 & Organ donor \\
\hline $\mathrm{M} / 45$ & Blunt & 13 & 22 & 16 & Hemothorax & 70 & 43 & Neurological deficit $(+)$ \\
\hline $\mathrm{F} / 22$ & Blunt & 9 & 15 & 22 & Brain & 88 & 47 & Neurological deficit (-) \\
\hline $\mathrm{M} / 38$ & Penetrate & 1 & 168 & 16 & Hemothorax & 10 & 1 & Neurological deficit $(-)$ \\
\hline $\mathrm{M} / 75$ & Blunt & 15 & 29 & 54 & Hemothorax & 16 & 16 & $\begin{array}{l}\text { Neurological deficit }(+) \\
\text { Deceased after } 16 \text { days }\end{array}$ \\
\hline
\end{tabular}

CPR time cardiopulmonary resuscitation, ISS Injury Severity Score, ICU intensive care unit, and LOS length of stay

pneumothorax, clavicle fracture, cervical and thoracic spine fracture, and multiple deep lacerations. She underwent many operations conducted by an orthopedic surgeon and recovered well without neurological deficit. Another surviving patient was a 38-year-old man who was transferred from a local hospital. He was stabbed with a knife in the left anterior chest wall, and a massive hemothorax was identified. He was transferred to our center by helicopter and directly moved to OR. Just before operation, cardiac arrest was identified and approximately $1 \mathrm{~min}$ of CPR was performed before preparing for RT. The patient was diagnosed with massive hemothorax due to internal thoracic artery injury, intercostal artery injury, pericardium laceration, and diaphragm laceration. Simultaneous thoracotomy and laparotomy were performed because the diaphragm was opened till the abdominal cavity, but no definite abdominal organ injury was observed. The patient recovered well without any neurological deficit.

\section{Discussion}

In the present study, the 24-h survival rate of RT was $8.1 \%$ and overall survival rate was $4.8 \%$. Sign of life was significantly associated with ROSC after RT, regardless of CPR time.

Our results demonstrate that $4.8 \%$ of patients who were discharged had survived, which is a low proportion but comparable with outcomes in previous studies, which demonstrated overall survival of $7-10 \%$ [12, 13]. In blunt trauma, RT remains controversial. Moore et al. [3] demonstrated that the overall survival rate of RT has improved to approximately $14 \%$, but penetrating trauma was associated with a better outcome than blunt trauma. In a recent meta-analysis on blunt trauma, only 21 of 1369 $(1.5 \%)$ patients survived with a good neurological outcome after RT [14]. In addition, Moriwaki et al. demonstrated that 13 of $408(3.2 \%)$ patients survived after blunt trauma with prehospital cardiac arrest after RT [7]. These patients present vital signs at the time of injury or in the emergency room. In Korea, the trauma mechanism in most cases is blunt force [4]. In addition, the trauma treatment system was not fully developed and the trauma center was only recently constructed [15]. Nevertheless, the outcome was comparable to that in developed countries and it may improve after the trauma treatment system is completely developed.

Indication of RT is important. It results in improved outcomes, as well as prevents waste of resources. Passos et al. [16] reported that among 63 cases of inappropriate RT, three cases comprised needle-stick injuries, which involved the use of $335 \mathrm{U}$ of blood products and occupied six OR spaces. In the present study, approximately $1000 \mathrm{U}$ of blood products were used for non-survivors. Indication of RT in our center was blunt trauma with prehospital cardiac arrest time of $<10 \mathrm{~min}$ because short CPR time is associated with a chance of ROSC. However, there were 17 patients with prehospital cardiac arrest time of $>10 \mathrm{~min}$. The longest prehospital cardiac arrest time was $15 \mathrm{~min}$. In an emergency situation, accurate prehospital cardiac arrest time cannot be calculated and is usually assumed to be approximately $10 \mathrm{~min}$, which is usually the time taken to reach the hospital from the injury. Moreover, trauma surgeons are required to make a prompt decision regarding $\mathrm{RT}$, and most often, there is not enough time available to discuss CPR time with the EMS personnel. Sometimes, EMS personnel are unsure of the exact prehospital CPR time. Sign of life could be a good indicator in this situation. In the present study, patients who presented sign of life in the trauma bay had a significantly high chance of ROSC. Two patients with cardiac arrest time of $>10$ min survived after RT, although severe neurological deficit was observed; however, they presented sign of life in the trauma bay. Furthermore, recent guidelines recommend against RT without the presence of sign of life, especially in blunt trauma [10, 17]. Therefore, sign of life should be considered as an indication regardless of CPR time. Using this indication, the 24-h survival rate was $13.5 \%$ and overall survival rate was $8.1 \%$. 
Although two cases of RT were performed in the helicopter, they were not conclusive procedures. Matzumoto et al. [18] reported that 44 cases of emergency RT were performed in the helicopter but no patients survived. However, ROSC rate was significantly high and two cases in our study also presented ROSC. On the other hand, surgical procedures, such as cardiac suture, are limited and blood product is not available in helicopters. If cardiac injury is observed, there may be no method available for treatment. Further studies are needed to evaluate the feasibility of performing RT in helicopters.

In the present study, we analyzed 20 patients who were transferred from local hospitals. Their median admission time from the injury was 157 [120-188] min. If they were admitted to trauma centers earlier, RT may not have been required. Early hemorrhagic control is important in trauma patients, especially in those with life-threatening bleeding [19]. A regional level I trauma center was constructed since 2012, but the trauma system, including triage, has not yet been developed. RT can be performed to treat only a few people, but with an effective trauma system, more people can be treated without RT.

The limitations of this study include its retrospective nature and small number of patients, especially with penetration injuries. In addition, the outcomes of three patients, who were examined before the trauma center was built, were included in our study. However, during this period, the RT indication did not change. RT was performed by various trauma surgeons; therefore, surgical skills and RT time for all cases may be different.

In conclusion, RT in a Korean trauma center remains challenging and the outcome of RT was less favorable than that in developed countries. This may be because of the high proportion of blunt traumas and inappropriate indication for RT. Because ROSC after RT is strongly associated with the presence of sign of life, sign of life may be considered as an indication for RT regardless of prehospital CPR time.

\section{Compliance with ethical standards}

Conflict of interest The authors declare that they have no conflict of interest.

\section{References}

1. Moore EE, Feliciano DV, Trauma Mattox KL (2017) In: Tsai PI, Wall JM Jr, Mattox KL (eds) Trauma thoracotomy: general principles and techniques. McGraw-Hill education, New York, pp 473-478

2. Pust GD, Namias N (2016) Resuscitative thoracotomy. Int J Surg 33:202-208
3. Moore HB, Moore EE, Burlew CC et al (2016) Establishing benchmarks for resuscitation of traumatic circulatory arrest: success-to-rescue and survival among 1,708 patients. J Am Coll Surg 223:42-50

4. Hong J, Lee WK, Park H (2006) Change in causes of injuryrelated deaths in South Korea, 1996-2006. J Epidemiol 21:500-506

5. Park JM (2016) Outcomes of the support services for the establishment of regional level 1 trauma centers. J Korean Med Assoc 59:920-930

6. Aso S, Matsui H, Fushimi K et al (2017) Resuscitative endovascular balloon occlusion of the aorta or resuscitative thoracotomy with aortic clamping for noncompressible torso hemorrhage: a retrospective nationwide study. J Trauma Acute Care Surg 82:910-914

7. Moriwaki Y, Sugiyama M, Yamamoto T et al (2011) Outcomes from prehospital cardiac arrest in blunt trauma patients. World $\mathrm{J}$ Surg 35:34-42. https://doi.org/10.1007/s00268-010-0798-4

8. Suzuki K, Inoue S, Morita S et al (2016) Comparative Effectiveness of emergency resuscitative thoracotomy versus closed chest compressions among patients with critical blunt trauma. A nationwide cohort study in Japan. PLoS One 11:e0145963

9. Burlew CC, Moore EE, Moore FA et al (2012) Western Trauma Association critical decisions in trauma: resuscitative thoracotomy. J Trauma Acute Care Surg 73:1359-1363

10. Seamon MJ, Haut ER, Van Arendonk K et al (2015) An evidence-based approach to patient selection for emergency department thoracotomy: a practice management guideline from the Eastern Association for the Surgery of Trauma. J Trauma Acute Care Surg 79:159-173

11. Jung KW, Huh Y, Lee JC et al (2016) Reduced mortality by physician-staffed HEMS dispatch for adult blunt trauma patients in Korea. J Korean Med Sci 31:1656-1661

12. Owen JJ, Sne N, Coates A et al (2015) Outcomes of emergency department thoracotomy in a tertiary care Canadian trauma centre. CJEM 17:353-358

13. Rhee PM, Acosta J, Bridgeman A et al (2000) Survival after emergency department thoracotomy: review of published data from the past 25 years. J Am Coll Surg 190:288-298

14. Slessor D, Hunter S (2015) To be blunt: are we wasting our time? Emergency department thoracotomy following blunt trauma: a systematic review and meta-analysis. Ann Emerg Med 65(297-307):e216

15. Kim J, Heo Y, Lee JC et al (2015) Effective transport for trauma patients under current circumstances in Korea: a single institution analysis of treatment outcomes for trauma patients transported via the domestic 119 service. J Korean Med Sci 30:336-342

16. Passos EM, Engels PT, Doyle JD et al (2012) Societal costs of inappropriate emergency department thoracotomy. J Am Coll Surg 214:18-25

17. Millin MG, Galvagno SM, Khandker SR et al (2013) Standards. Withholding and termination of resuscitation of adult cardiopulmonary arrest secondary to trauma: resource document to the joint NAEMSP-ACSCOT position statements. J Trauma Acute Care Surg 75:459-467

18. Matsumoto H, Mashiko K, Hara Y et al (2009) Role of resuscitative emergency field thoracotomy in the Japanese helicopter emergency medical service system. Resuscitation 80:1270-1274

19. Alarhayem AQ, Myers JG, Dent D et al (2016) Time is the enemy: mortality in trauma patients with hemorrhage from torso injury occurs long before the "golden hour". Am J Surg 212:1101-1105

Publisher's Note Springer Nature remains neutral with regard to jurisdictional claims in published maps and institutional affiliations. 